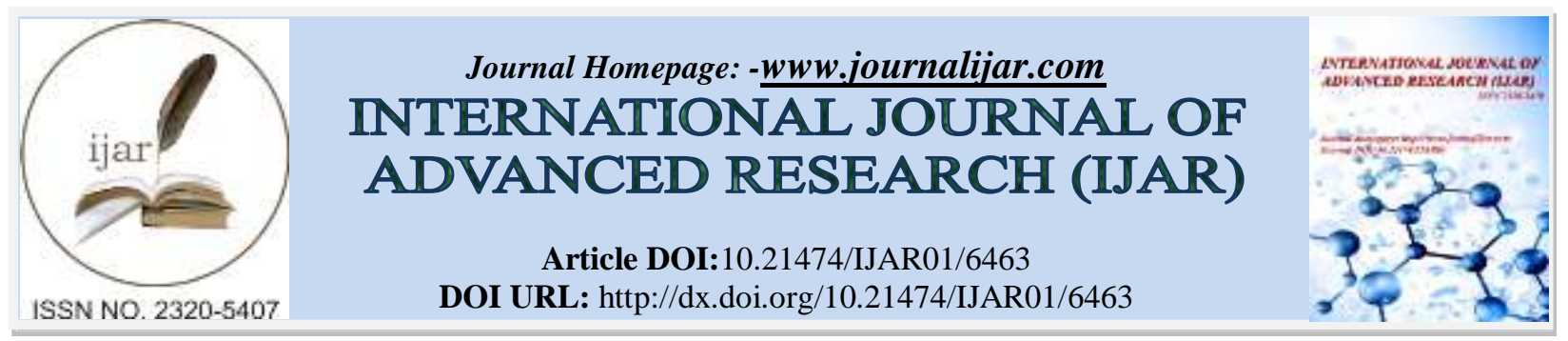

RESEARCH ARTICLE

\title{
ANALYTICAL STUDY OF FACIAL NERVE INJURY IN TRAUMATIC FACIAL NERVE PALSY.
}

\author{
Dr. N. Dhinakaran ${ }^{1}$, Dr. B. Muthu Kumar ${ }^{2}$ and Dr. M. Robin Richards ${ }^{3}$. \\ 1. MS ENT,Professor and HOD, Dept of ENT, Madurai Medical College, Madurai. \\ 2. MS ENT, Assistant Professor, Dept of ENT, Madurai Medical College, Madurai. \\ 3. PG in ENT, Madurai Medical College, Madurai.
}

\section{Manuscript Info}

Manuscript History

Received: 07 December 2017

Final Accepted: 09 January 2018

Published: February 2018

Keywords:-

Facial Nerve, Road Accident, temporal bone fracture.

\begin{abstract}
Traumatic facial paralysis is not altogether uncommon. Though incidence of postoperative facial palsy has declined considerably in recent years, thanks because of improvement in microsurgical techniques for mastoid surgery, yet accidents still happen occasionally. However, there seems to be a higher occurrence of facial paralysis due to increase in road side accidents. Results of surgery are rewarding, though recovery may not be complete. Present paper describes our experience of treating 20 such cases. However, cases requiring nerve decompression procedures only have been included in the present study. Surgical technique has been briefly discussed along with relevant review of literature.
\end{abstract}

Copy Right, IJAR, 2018,. All rights reserved.

\section{Introduction:-}

Facial paralysis has been a subject of particular interest to the Otolaryngologists for several decades. Role of surgical intervention in traumatic facial palsy is clearly established. Most authors are of opinion that the facial nerve should be explored as early as possible in cases of complete paralysis of immediate onset following an injury, whether due to mastoid surgery or due to fracture of the temporal bone.

Techniques of the facial nerve surgery were originally described by Ballance and Duel (1938), and were later developed by Bunnel (1937); Martin (1955); Kettel (1957); Jonkess (1972) ; Lathrop (1965) and Sade (1975). The goal common to all these operations to repair the injured facial nerve, be it by decompression, direct anastomosis, re-routing, or a free nerve graft. Aim of the present paper is to critically evaluate different factors which may influence quality of recovery of the facial movements following a nerve decompression in traumatic facial nerve palsy

\section{Materials And Methods:-}

This study is based on experience of 20 patients in whom facial nerve decompression was performed for traumatic facial palsy in Department of ENT, Madurai Medical College, Madurai between 2016 -2017. The aim of this study is to evaluate the distribution and type of temporal bone fractures in patients presenting with traumatic facial nerve palsy, interval between the onset of the injury and the time of onset of facial palsy. Under general anesthesia, by a postauricular incision, cortical mastoidectomy done. Posterior canal wall was lowered by removing the facial bridge and lowering the facial ridge. The bony fragments impinging of the facial nerve was removed and the facial nerve was decompressed 270 degrees. 


\section{Observations:-}

All patients were subjected to a thorough clinical examination before the facial nerve exploration. Audiological tests were done in all except a small number of head injury cases which were operated the same day as emergency procedures. Approximate site of the lesion of the facial nerve was determined by Schirmer's test and evaluating sensation of the taste. Tests for salivary flow was not carried out. CT temporal bones were done in cases of accidental injuries and the site of the fracture was identified. Electrodiagnostic tests such as the nerve excitability and strength duration were not carried out routinely in the present series.

Age incidence of the patients is described in Table I.

In facial paralysis due to accidental injuries, a majority of the patients were between 21-50 years. Youngest patient in the series was a child of 20 years while the oldest patient was 57 years of age. There were 18 male and 2 female patients.

\begin{tabular}{|l|l|l|}
\hline Age(years) & Facial Palsy in RTA & Percentage $(\%)$ \\
\hline$<10$ & 0 & 0 \\
\hline $11-20$ & 1 & 5 \\
\hline $21-30$ & 5 & 25 \\
\hline $31-40$ & 6 & 30 \\
\hline $41-50$ & 5 & 25 \\
\hline$>50$ & 3 & 3 \\
\hline
\end{tabular}

\begin{tabular}{|l|l|l|}
\hline Sex & Facial Palsy in RTA & Percentage \\
\hline Male & 18 & 90 \\
\hline Female & 2 & 10 \\
\hline
\end{tabular}

Table II describes the time interval between onset of facial paralysis and subsequent nerve decompression. Most of the patient presented to us within one week of injury.

\begin{tabular}{|l|l|}
\hline Interval Between Injury and Surgery & Facial Palsy in RTA \\
\hline Within 48 hrs & 7 \\
\hline Within 1 week & 10 \\
\hline Within 1 month & 2 \\
\hline More than 1 month & 1 \\
\hline Total Number of cases & 20 \\
\hline
\end{tabular}

Table 3:- describes the site of facial nerve injury in the temporal bone.

At the nerve decompression, site of the facial nerve injury was located in Horizontal segment of the facial nerve in as many as 15 cases (75\%). 3 cases (15\%) the lesion was found in geniculate ganglion of the facial nerve.

\begin{tabular}{|l|l|}
\hline Site of lesion & No of Patients \\
\hline Labynthine segment & 1 \\
\hline Geniculate ganglion & 3 \\
\hline Tympanic segment & 15 \\
\hline Vertical Segment & 1 \\
\hline
\end{tabular}

All patients were given similar treatments including antibiotics and support treatments. Stitches were removed after a week and facial function rehabilitation exercises began.Among 20 patients who had facial nerve decompression, 19 patients recovered from the palsy.

\section{Discussion:-}

Approximately $15-25 \%$ of the longitudinal and $50 \%$ of the transverse temporal bone Fractures result in facial Paralysis. Facial nerve decompression in temporal bone fractures can significantly improve clinical outcomes. Facial nerve decompression led to good results within 3 months after injury. If early decompression of TFP was missed, late decompression could still be applied with certain efficacy. We think that surgical intervention should be done as soon as possible. If the patients has missed the chance of early intervention, surgery should be done when EMG shows fibrillation potentials. 
On the surgical approach, the mastoid approach is used for tympanic and vertical segment injury, the external ear canal approach for horizontal segment injury with combined ossicular chain disruption in longitudinal temporal bone fractures, the middle cranial fossa approach for geniculate ganglion and labyrinthine segment or the internal auditory canal segment injury with good hearing and vestibular function; and the mastoid-middle cranial fossa approach for decompression of the entire course. When there is completely normal hearing and the injury site is above the geniculate ganglion, translabyrinthine approach is usually recommended.

\section{References:-}

1. AG Kerr and GDL Smyth. Ear Trauma: Scott-Brown's Otolaryngology, Butterworth International Edition 1987;5:172-84.

2. C Hartley, AD Mendelow. Post traumatic bilateral facial palsy. J Laryngol Otol 1993;107:730-1.

3. Dragoljub Popovic, Milan Stankovic, Zorica Popovic, Dusan Mulisavljevic. Traumatic facial palsy. Facta Universitatis Series, Medicine \& Biology 2003;10:145-7.

4. JP Bebear and M Bagot D'Arc. Management of Traumatic Facial palsy. Traumatology of skull base, edited by M. Samii and J Brihaye. Springer Verlag New York 1983:152-4.

5. PP Devriese. Facial paralysis after trauma of the skull. In, Samii M and Brihaye J (eds). Traumatology of the skull base. Springer Verlag New York 1983:155-63.

6. Jackler RK; Facial, auditory, and vestibular nerve injuries associated with basilar skull fractures.In, Youman JR (ed) Neurological Surgery. WB Saunders 1990;3:2305-16.

7. Sherwen PJ, Thong NC. Bilateral facial nerve palsy : A case report and literature review. J Otolaryngol 1987;16:28-32.

8. Zhigang Cai, Guangyan Yu, Daquan Ma, Jing Tan, Zhaohui Yang, Xiaoming Zhang. Experimental studies on traumatic facial nerve injury. J Laryngol Otol 1998;112:243-247. 